Vol. 11 (2): 263-268 (2021)

\title{
SPECIES COMPOSITION OF MOSSES AS A PROXY OF ACTUAL STATE OF FOREST AND A FORECAST OF THEIR DEVELOPMENT WITHIN EXTRAZONAL (PAGAGENESE) STEPPE (illustrated by Western Pre-Baikal)
}

\author{
Alexander Sizykh ${ }^{*}$

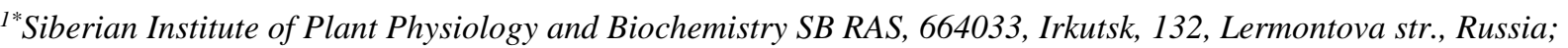 \\ *Corresponding Author Alexander Sizykh, e-mail: alexander.sizykh@gmail.com;
}

Received December 2020; Accepted January 2021; Published March 2021;

DOI: $\underline{\text { https://doi.org/10.31407/ijees11.210 }}$

\begin{abstract}
Studies of the role of mosses as of proxies of actual state of the forests in the structural-dynamic organization of vegetation in extrazonal (paragenese) steppe allowed to find out the trends of the development of taiga-steppe coenoses within zonal taiga of Western Pre-Baikal.
\end{abstract}

Key words: mosses, forest, extrazonal (paragenese) steppe, forecast, Pre-Baikal 